\title{
SOBRE LA DATACIÓN Y LÍMITES DE LAS TERRAZAS DE CULTIVO. ALGUNAS OBSERVACIONES DE CAMPO
}

\author{
Pablo Giménez Font \\ MedSPai ${ }^{1}$ - Universidad de Alicante
}

\section{RESUMEN}

A través de una serie de estudios de caso, en estas líneas se plantean unas reflexiones metodológicas en torno a la datación de determinados sistemas de terrazas de cultivo y los límites que éstos alcanzaron en la montaña mediterránea. Para ello se ilustran una serie de ejemplos, referidos especialmente a la Serra d'Aitana, donde las vertientes aterrazadas alcanzan dimensiones excepcionales.

Palabras clave: terrazas de cultivo, historia del paisaje, Sierra de Aitana (Alicante)

\section{ABSTRACT}

Dating and limits of cultivation terraces. Some field observations.

Through a series of case studies in this paper some methods for dating terraces and the limits achieved in the Mediterranean mountains arise. For this purpose a series of examples, especially related to the Serra d'Aitana, where the terraced slopes reach exceptional size are illustrated.

Keywords: cultivation terraces, landscape history, Sierra de Aitana (Alicante, Spain)

1. Grupo de Investigación sobre Medio, Paisaje y Sociedad. Centro Iberoamericano de la Biodiversidad - Instituto Interuniversitario de Geografía - Departamento de Análisis Geográfico Regional y Geografía Física. 


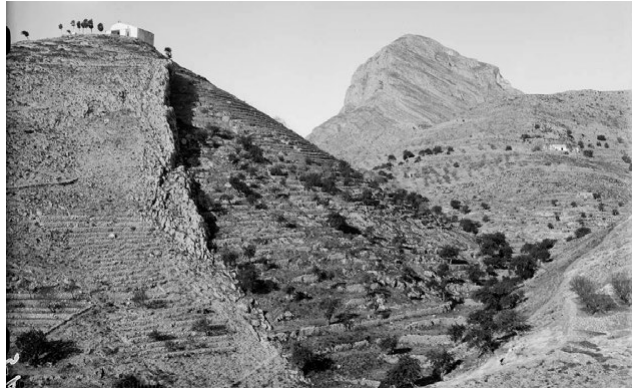

Figura 1: Tossal de Santa Llùcia, Xàbia (S. ${ }^{\text {a }}$ del Montgó): terrazas de la segunda mitad del siglo XIX, destinadas al cultivo de la vid y mayoritariamente abandonadas a principios del siglo xx. Antonio Passaporte (1927-1936) Archivo Loty, Fototeca del Patrimonio Histórico (Ministerio de Cultura).

Las presentes reflexiones son fruto de lecturas, conversaciones y, sobre todo, de la vivencia personal del paisaje de terrazas de la montaña survalenciana. Pretenden ser un homenaje al profesor Alfredo Morales, quien supo inculcarme algunos valores que han sido determinantes a la hora de dirigir mis temas de investigación: el valor de la Historia y la observación en el campo, atendiendo especialmente a la percepción y valoración que del espacio tuvieron nuestros antepasados. Sólo tratando de mirar el territorio bajo los parámetros de un pasado no tan lejano y despojándonos de muchos preceptos contemporáneos (y urbanos), es posible entender el funcionamiento de los sistemas de terrazas y acercarnos a sus orígenes. Leer correctamente este singular paisaje y escuchar a los protagonistas del mismo, herederos de los artífices que lo hicieron posible, resulta la base fundamental para comprender, mínimamente, la organización y aprovechamiento de las vertientes. Para ello se ha querido centrar el análisis en la datación y extensión de los sistemas de terrazas, dos aspectos clave e insuficientemente tratados, dado que gran parte de las publicaciones al respecto se refieren a cuestiones vinculadas a los procesos geomorfológicos derivados del abandono de las terrazas y de iniciativas para la conservación de las mismas².

\section{SOBRE LAS DIFICULTADES DE DATACIÓN: DESDE CUÁNDO, HASTA DÓNDE}

Uno de los problemas centrales del estudio de las terrazas está en su datación, puesto que, a grandes rasgos, presentan una técnica constructiva de carácter atemporal. La cuestión no es baladí cuando su levantamiento viene a representar un proceso de antropización del medio sin parangón en la milenaria historia de muchos territorios. Esta reconstrucción de las vertientes tuvo unas repercusiones tan determinantes en el paisaje y los procesos geomorfológicos que resulta

2. Sobre ambas cuestiones, se podrían destacar dos publicaciones de A. Morales, en coautoría con J.A. Marco (1995) y M. Hernández (2012). Una buena síntesis reciente del estado de la cuestión puede encontrarse en T. Lasanta et al. (2013), aunque la mejor recopilación de estudios sobre terrazas se puede leerse en la última versión (octubre de 2014) de References on agricultural terraces (Spain), elaborado por el Centro de Estudios de la Desertificación (Universitat de València) para la International Terraced Landscapes Alliance (ITLA). Disponible en http:// www.alpter.net/Bibliographic-references-on,678.html?lang=en 
fundamental conocer cuándo $\mathrm{y}$ hasta dónde han llegado los aterrazamientos. Pese a ello, se trata de un desafío científico importante y nada sencillo, que en la actualidad entronca bien en ciencias de frontera disciplinaria como la geografía histórica y su derivada más reciente, la arqueología del paisaje.

De esta forma, para determinar la edad de las terrazas se requiere de la participación de disciplinas y métodos diversos, en clara comple-

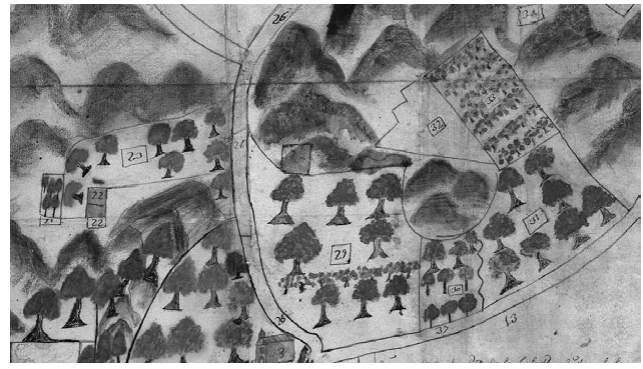

Figura 2. Ombria de Bodoix (Pego): establecimientos del siglo XVIII (hasta 1774), en la partida conocida entonces como Els Marges (Barranc de La Canal). Arxiu del Regne de València. M y P. n. ${ }^{\circ} 235$. mentariedad. Un primer conjunto de técnicas están relacionadas con la arqueología, aunque la terraza en sí mismo ofrece materiales descontextualizados por el laboreo y la remoción de tierras, en ocasiones provenientes de otros lugares para rellenos artificiales del bancal. En algunos casos concretos restos vegetales -especialmente carbones- y sedimentos, pueden facilitar dataciones precisas pero que hay que contextualizar correctamente para no caer en equívocos de partida.

Éstas suelen resultar evidencias fiables aunque costosas y localizadas, por lo que hay que buscar otras fuentes y métodos de análisis. La documentación histórica - escrita, gráfica y fotográfica- presenta enormes posibilidades en algunos territorios: la historia agraria ha trabajado diversos documentos -cartas puebla, cabreves, protocolos notariales, amillaramientos, catastro- que, junto con la toponimia actual y antigua, nos permite localizar y datar establecimientos de tierras.

Los testimonios contemporáneos son igualmente ricos, con especial significación en tierras valencianas de las Observaciones de Cavanilles -testigo de excepción de la transformación del territorio durante el siglo XVIII- o de otras publicaciones menos explotadas, como es el caso de la obra de Beramendi, que describe fascinado la ingente construcción de terrazas a su paso por las tierras de Aitana y Mariola:

Es de admirar lo que se esmeran en éste, pues sacan la tierra que está a media vara, o tres palmos de la superficie, para ponerla encima cuando se desustancia la que había; supliendo al mismo tiempo la desigualdad del terreno con paredes fuertes de piedra, llamadas márgenes, que lo contengan, formando con ellos graderías o banquetas hasta la cima de los montes (que llaman bancales) y en muchos de estos cuesta más el margen que su valor, pues están hechos con el mayor primor y solidez, sin embargo de no tener betún, al modo que fabrican 


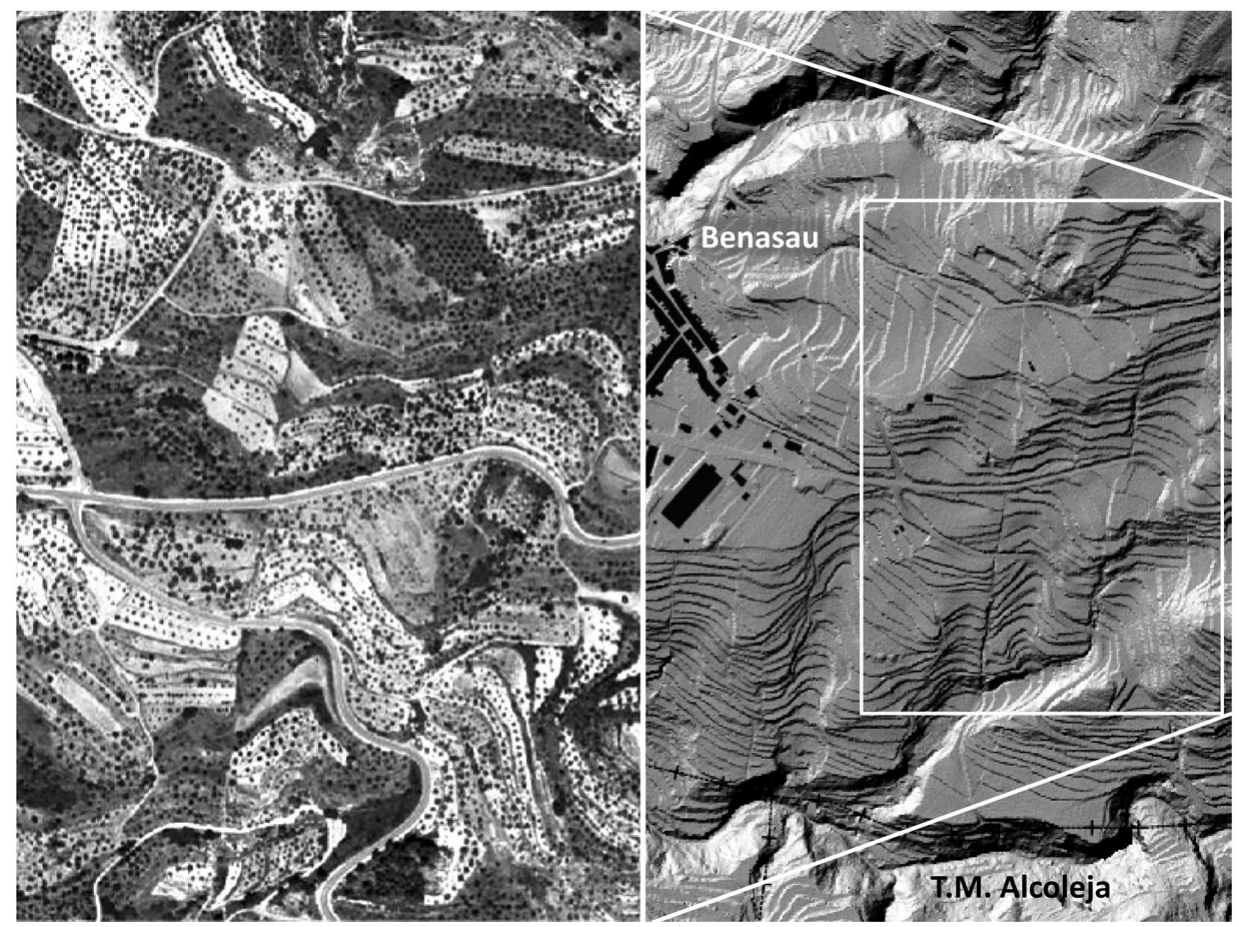

Figura 3. El estudio arqueomorfológico permite reconocer trazas viarias y en el parcelario que pueden articular sistemas de terrazas como las que observamos en Benasau, entre el Riu Frainos y el Barranc de les Solsides. Algunos sistemas de terrazas están articulados por trazas geométricas, sin funcionalidad en el presente, pero que podrían evidenciar procesos de colonización dirigidos, de época medieval o anterior. Elaboración propia a partir del visor Terrasit (ICV).

los romanos algunas de sus obras, pero no por ello dejan de tener la elevación necesaria y todavía más fortaleza y hermosura que si lo hicieran de obra ${ }^{3}$.

Testimonios que se suceden también en el siglo XIX e, incluso, en los inicios del xx, conectando directamente con la memoria oral. En ocasiones esta rica fuente ofrece sorpresas y permite comprobar la relativa juventud de terrazas aparentemente antiguas, construidas con técnicas tradicionales durante las primeras décadas del siglo. Algunas marcas epigráficas -normalmente fechas e iniciales- confirman o alteran hipótesis previas sobre la edad de un sistema de terrazas. En otras ocasiones es la propia técnica empleada en la construcción de muros la que ofrece datos. No es común, pero la presencia de opus espicatum, la utilización de grandes piedras -bancales ciclópeos- o evidencias de barrenado pueden resultar determinantes para la datación, o al menos para descartar 


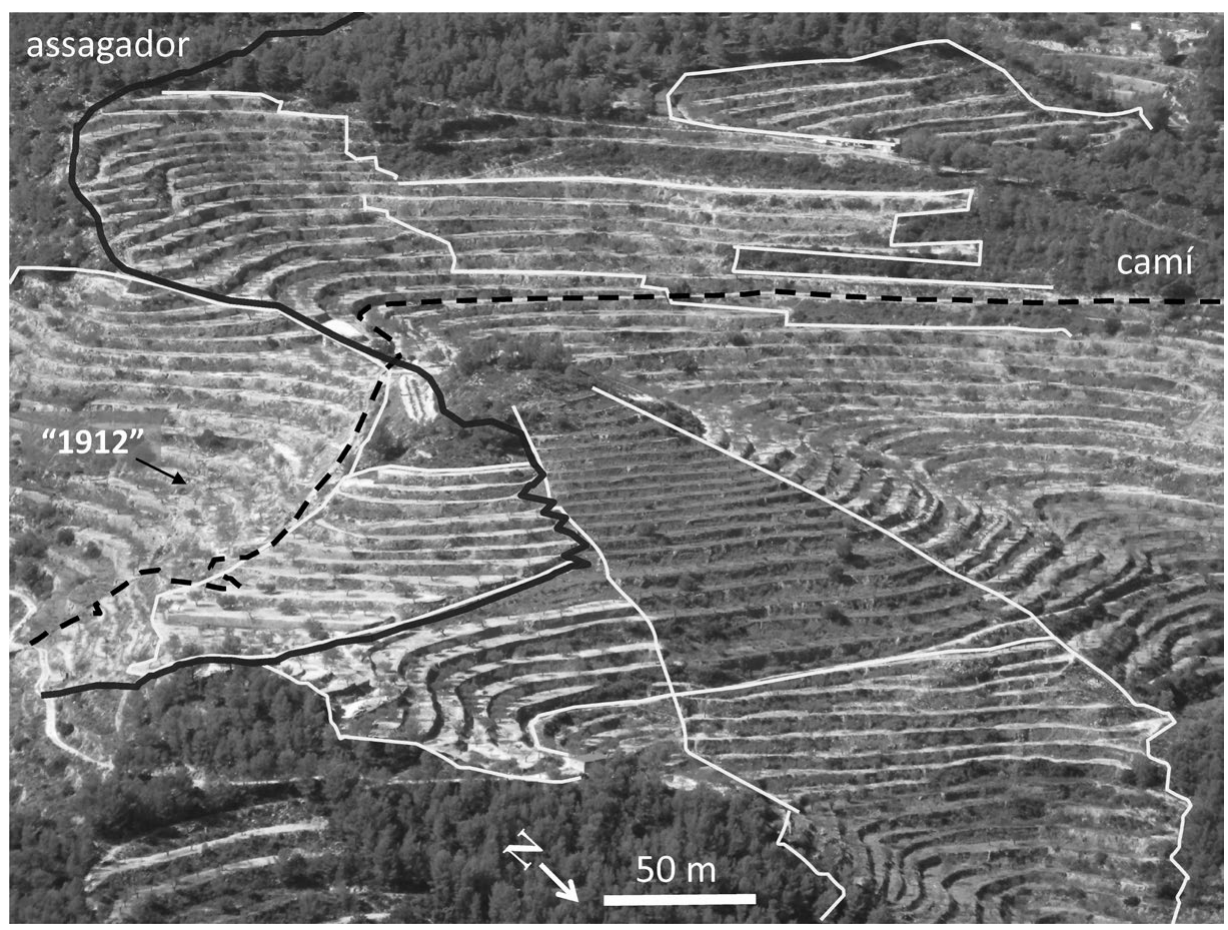

Figura 4. Un análisis constructivo-evolutivo de sistemas de terrazas se basa en diferentes criterios morfológicos: técnicas de construcción y tamaño de los bancales, orientación de las terrazas, contactos entre sistemas (contramarges), correspondencia de dichos contactos con límites de propiedad y presencia de caminos tradicionales (trazo discontinuo) o vías pecuarias (línea de color morado). En uno de los muretes se ha localizado una inscripción con la fecha 1912, mientras que la documentación manejada indica que a principios del siglo XVIII ésta era una zona poco roturada. Evidencias que, en conjunto, permiten plantear hipótesis sobre distintos periodos de construcción (línea amarilla).

Apunte para la Serra de l'Aguilar (Sella). Elaboración propia sobre una imagen de 2015.

hipótesis previas. Con todo, la técnica que posiblemente ofrece una visión más completa del proceso de construcción de sistemas de terrazas es el análisis morfológico - o arqueomorfológico- del parcelario, un método de aplicación fiable gracias a la numerosa colección de fotografías aéreas históricas pero con una interpretación, en ocasiones, un tanto arriesgada. En buena lógica, el estudio del parcelario -a través de elementos estructurales como caminos, vías pecuarias o límites de propiedad (contramarges) ${ }^{4}$ y jurisdiccionales- se complementa con las técnicas anteriores y, como mínimo, puede ofrecer datos sobre las fases de configuración de determinados sistemas de terrazas.

4. En otra publicación me he referido a determinados contactos entre sistemas de terrazas, denominados contramarges, como posibles indicadores de fases temporales de construcción (Giménez, 2013). 


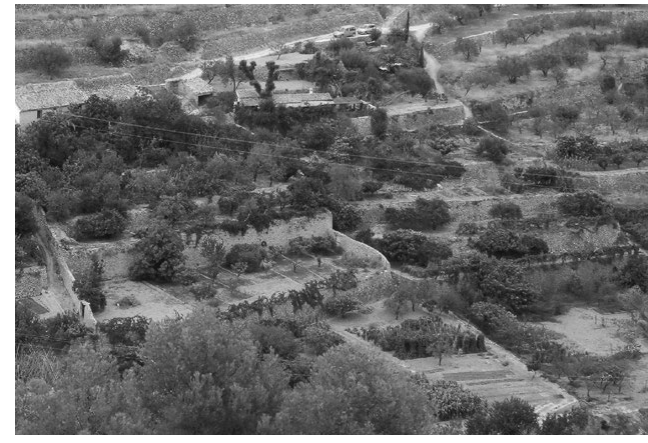

Figura 5. En ocasiones, el repartimiento señorial tras la Conquista se refleja en una división del sistema de terrazas de regadío en lotes transversales a una acequia, generalmente siguiendo pautas métricas reguladas en la legislación foral. En la partida de El Llinar, huerta de Sella, las hijuelas de la acequia mayor marcan un parcelamiento en forma de bandas perpendiculares separadas por Cordes de 20 brazos reales (equivalente aproximadamente a $41 \mathrm{~m})$. Fotografía del autor (2013).

La distribución de agua para riego, tanto de derivación fluvial como directamente de manantiales y galerías, se ha considerado como un marcador histórico relevante, especialmente en las zonas de montaña donde las terrazas regadas por una acequia pueden tener un origen antiguo. Las formas más irregulares -orgánicas, según diversos autores- parecen indicar procesos de construcción más espontáneos, ligados a pequeñas comunidades e iniciativas campesinas; otras, con un carácter marcadamente geométrico, pueden identificar procesos más dirigidos, fruto de empresas de colonización más generales, tanto medievales como modernas, si no anteriores ${ }^{5}$. Algunos estudios detallados, como los realizados por Josep Torró, se basan en el análisis de sistemas de regadío andalusí y sus terrazas asociadas, que posteriormente fueron ampliadas bajo el dominio cristiano ${ }^{6}$. El amplio abanico de estudios de caso en al-Andalus, en el marco de la escuela creada por Miquel Barceló, permite contar con un sólido corpus metodológico para emprender análisis sobre los extensos espacios de terrazas que todavía están sin estudiar. La estimación de las terrazas presentes en época andalusí permite, en último término, valorar la magnitud del proceso de aterrazamiento posterior, tanto en la baja edad Media como en la Moderna; pero, para ello, el inventario y cartografiado exhaustivo de los componentes de los sistemas de regadío -fuentes/azudes, acequias o balsas, entre otros- resulta fundamental para cualquier intento de análisis.

\section{LOS LÍMITES DE LAS TERRAZAS}

Si no es posible contestar fácilmente a desde cuándo existen determinados sistemas de terrazas, tampoco es menos sencillo responder al hasta dónde se construyeron terrazas y si todas ellas convivieron activas en algún momento. No obstante, conociendo las características propias de la montaña mediterránea, y en especial de la valenciana, es razonable partir de la hipótesis del

\footnotetext{
5. A. Morales (1992)

6. J. Torró (2005 y 2010).
} 
máximo de expansión agraria alcanzado entre la segunda mitad del siglo XIX e inicios del XX. El desmoronamiento del Antiguo Régimen, las políticas liberalizadoras, el crecimiento demográfico y el contexto económico favorecieron que, en numerosos sectores, se alcanzaran los límites agro-técnicos al construir terrazas sobre sectores de pendientes y litologías totalmente inadecuadas. Gran parte de ellas se mantuvieron funcionales durante pocos años, debido a la escasa fertilidad y al fin de las coyunturas que las hicieron posible: la sobrepobla-

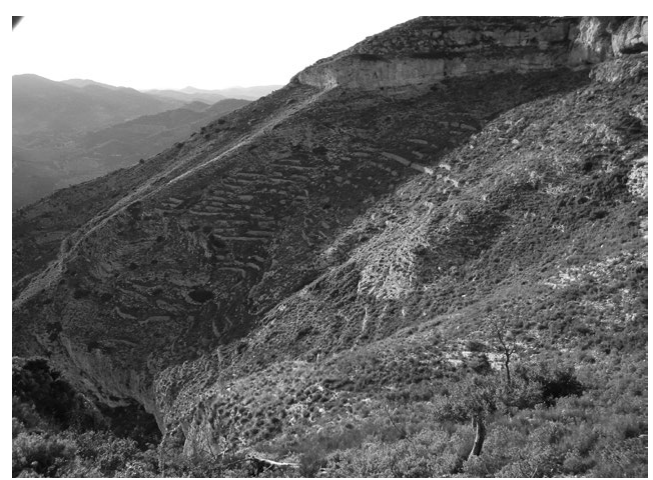

Figura 6. Terrazas en La Pileta (Penya de Sella), construidas en condiciones extremas sobre pendientes superiores al 70\%, entre las altitudes de 825 y $950 \mathrm{msnm}$. Algunas presentan dimensiones muy reducidas, válidas pese a ello para el cultivo de cereales y algún pie arbóreo de almendro o higuera. Fotografía del autor (2004). ción progresivamente terminó con las oleadas emigratorias y la filoxera alcanzó finalmente los viñedos valencianos. Algunas de ellas ya estaban abandonadas incluso a principios del siglo xx y el desmantelamiento de los muretes o la recolonización vegetal las hacen hoy en día casi inexistentes o irreconocibles.

Sin embargo la posibilidad de cartografiar todas aquellas terrazas que organizaron las vertientes en un momento determinado, resulta especialmente sugerente por la información de conjunto que puede aportar. Se logra así un negativo de las tierras roturadas para plantear una hipótesis de datación, justamente en el periodo de máxima intensificación, que podríamos situar en esa segunda mitad del siglo xIX e inicios del siglo xx. Es una datación finalista en cuanto que nos permite entender el proceso de abandono y algunos aspectos morfológicos de la posterior evolución de las terrazas. Pero, igualmente, es válida para estimar la reducción de los espacios incultos y la presión que se pudo ejercer sobre la vegetación que poblaba esos yermos, a partir de los cuales volvió a reproducirse sobre los antiguos campos de cultivo. Se logra así un modelo de expansión -iniciada muchas veces en la edad Media y fuertemente intensificada durante los siglos XVIII y XIX- y contracción -acelerada en la segunda mitad del siglo $\mathrm{xx}$ - que permite aproximarnos al estado general del paisaje vegetal histórico y entender la dinámica del paisaje actual.

No obstante, existen diversas dificultades de orden metodológico. La primera de ellas es conseguir cartografiar la totalidad de las terrazas con una inversión de tiempo y trabajo de campo razonable. Incluso en las fotografías aéreas históricas, con especial significación de las series A y B del Vuelo Americano 


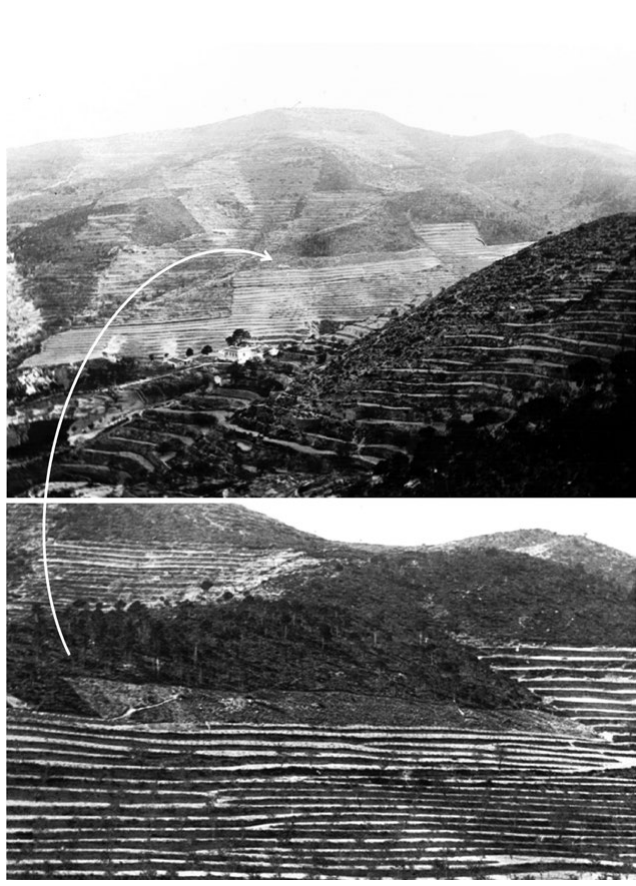

Figura 7. En este detalle de una imagen de los primeros años de la década de 1920 se aprecia una posible roturación de tierras de aprovechamiento forestal para la construcción de terrazas en $\mathrm{La}$ Rapella (Sella). Una imagen valiosa y muy poco común (Arxiu de Sella. Fons Rapella dels Senyorets)

(1945 y 1956), no es sencillo localizar determinadas terrazas cubiertas por la vegetación y, ocasionalmente, regularizadas por la erosión. Para ello se dispone en la actualidad de vuelos LiDAR cuyos puntos, correctamente interpretados, están resultando de gran utilidad para identificar antiguas terrazas incluso por debajo de densas masas forestales. Debidamente complementados con fuentes históricas y trabajos de reconocimiento en el campo, están permitiendo obtener cartografías precisas de las terrazas, con las morfologías y dimensiones cercanas a las originales ${ }^{7}$.

Igualmente, cabe considerar que no todos los espacios sin aterrazar fueron ajenos a la agricultura o, directamente, espacios de monte destinados a pastos, recolección de fibras o a la explotación forestal para madera, leñas y carbón. Los sectores incultos fueron mucho más permeables en cuanto a usos se refiere y han absorbido a lo largo de la historia procesos de crecimiento y decrecimiento de la agricultura, parcialmente imbricada con otros aprovechamientos. La presencia de espacios incultos obedece a una casuística compleja: generalmente se trata de espacios sometidos a elevadas pendientes y suelos raquíticos, salinos o excesivamente húmedos que limitaban los cultivos, pero en ocasiones también intervenían razones de tipo jurisdiccional e incluso de orden ecológico.

En este sentido, cabría detenerse en los canchales y depósitos de coluviones sometidos a fuertes pendientes. Representaron, mayoritariamente, un límite impreciso de la expansión de la agricultura en altura, mientras que la elevada movilidad del substrato impide en ocasiones valorar realmente la presencia o no

7. Vid. el sugerente trabajo de G. Sofia et al. (2014) y algunos ensayos propios en M. Moll y P. Giménez (2014). 


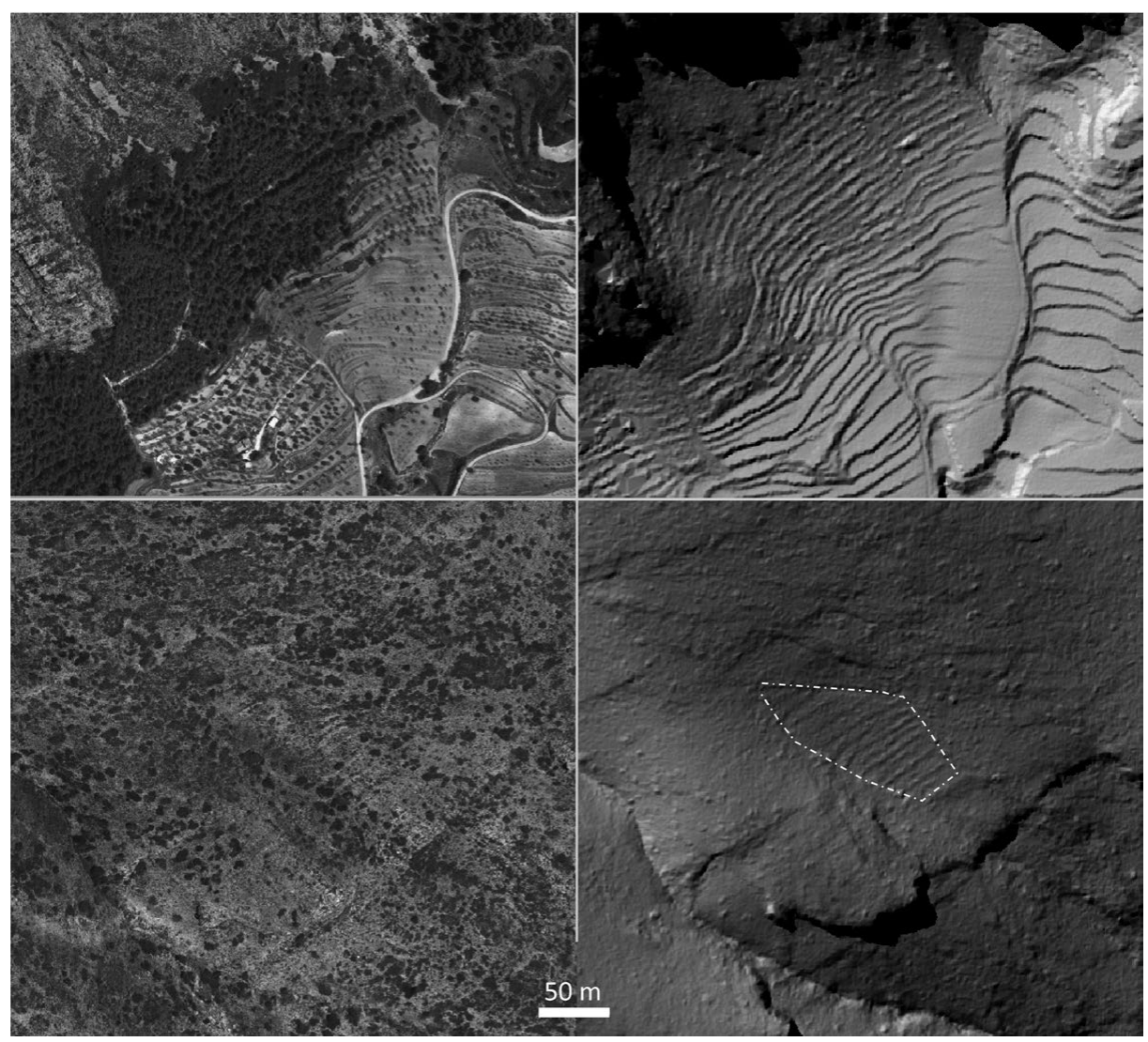

Figura 8. Aplicaciones de productos derivados de datos LiDAR, como el sombreado, nos permite identificar los límites y morfologías de espacios aterrazados, como estos de Muletes en el Barranc de l'Arc (imagen superior) o terrazas marginales difícilmente identificables mediante fotointerpretación no estereoscópica, como las del Barranc Fort (imagen inferior) Ambos ejemplos

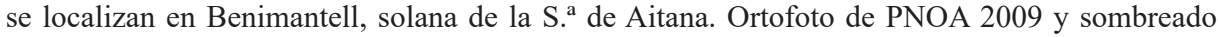
proporcionado por ICV.

de terrazas -muchas de ellas regularizadas- así como su funcionalidad ecológica en el mundo rural del pasado.

Los bancales construidos sobre pedrizas, canchales o runars -tanto de origen periglaciar como fruto de desprendimientos, al igual que materiales de coluvión más evolucionado- presentan una de las tipologías más sugerentes para el análisis. Tratándose de formaciones superficiales de elevada rugosidad y permeabilidad, hay dudas sobre su papel en la organización de las vertientes.

Sorprendentemente, estos espacios de elevada pendiente no siempre fueron escalonados, aunque sí cultivados. En la Serra d'Orxeta (figura 9) encontramos, sobre depósitos de coluvión, ejemplos excepcionales de plantaciones dispersas 


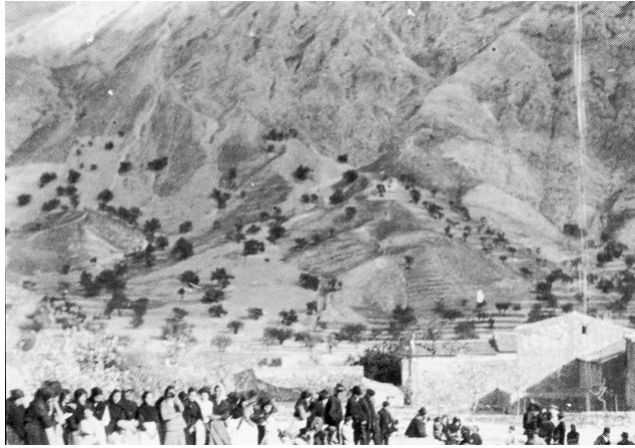

Figura 9. Detalle de la partida de El Garroferal, Serra d'Orxeta, en 1916: un ejemplo de la gestión de vertientes de elevada pendiente sin empleo de terrazas, con marcos de plantación abiertos y dispersos. En torno a la década de 1970 aquí se construyeron terrazas para el cultivo de almendro, hoy abandonadas (Arxiu Històric Municipal d'Orxeta. Colección Maestro Ángel Llorca).

de algarrobos, ocasionalmente vides, con evidencias de desbroce $y$, tal vez, arado. No se puede descartar tampoco la siembra de cereal en épocas de mayor necesidad. Las fotografías y vuelos históricos nos presentan una cobertura arbórea abierta de grandes ejemplares de algarrobo: la pendiente y el substrato limitan este espacio al aprovechamiento ganadero, pasto y algarrobas para el ganado mular y caballerías, ocasionalmente para consumo humano. En otros espacios más húmedos estos ejemplares arbóreos podrían ser carrascas, con el mismo fin. Teniendo en cuenta que, incluso a finales del siglo XIX, Orxeta era una pequeña población con una extensa y fructífera huerta sobre la que se centraban la mayor parte de los esfuerzos productivos ¿estamos ante una imagen representativa del estado general de las vertientes montañosas previo a la expansión agraria de los siglos XVIII y XIX?

En otros casos de estudio, encontramos canchales con bloques de mayor volumen y parcialmente aterrazados, posiblemente durante los siglos XVIII y XIX. En ocasiones el calibre de los derrubios no permitía el arado pero en muchos casos las parcelas eran despedregadas de los materiales más grandes, con lo que se construían gruesos muros (figura 10). Los bancales eran cultivados con cereales y admitían arbolado (vid y almendro, ocasionalmente algarrobo y olivo). Para el primer caso era necesaria la presencia de arcillas de descalcificación y gravas, mientras que en el segundo se necesitaba alcanzar cierto espesor edáfico, no demasiado profundo, para asegurar el enraizamiento y la humedad, sin duda el principal recurso de estos extremales.

En general, su abandono para la agricultura fue rápido y es difícil recuperar testimonios que permitan entender bien su papel en la explotación de una vertiente. No obstante algunas evidencias hacen pensar en el aprovechamiento de la vegetación natural, como carrascas y fresnos, que conviviría con los sembrados y frutales y de las que se obtendría bellota, madera y leña para las carboneras, algunas de las cuales se realizarían sobre plataformas o sitges situadas en las propias terrazas. Los portes y morfologías que hoy conservan estos árboles en numerosos canchales indican aprovechamientos forestales antiguos, podas e 


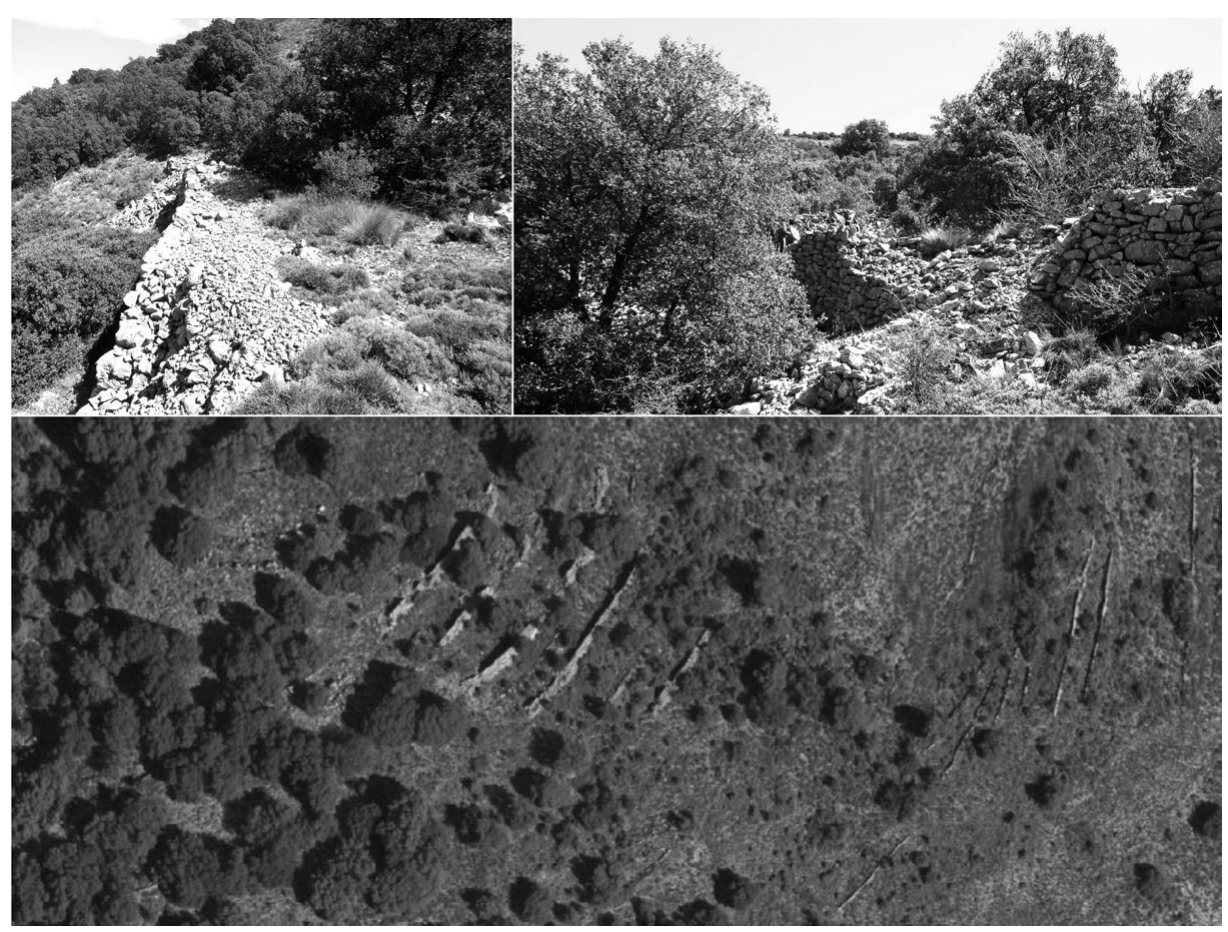

Figura 10. Terrazas sobre canchales en Alcoleja (Piscul, Aitana, $1.200 \mathrm{msnm}$ ). Nótese el despedregue y la acumulación de derrubios en los gruesos márgenes. La presencia de carrascas de porte arbóreo y evidencias de poda parecen relacionar la presencia de éste árbol con los bancales de los que formaban parte. Terrazas próximas se han podido datar a finales del s. XVIII. Fotografías del autor (2014) y ortofoto del PNOA 2009.

injertos que demuestran un papel importante en la organización tradicional del espacio. No resulta sencillo, por tanto, evaluar el sentido plenamente agrario de algunas de estas terrazas aunque la hipótesis más sólida indica que su expansión estuvo relacionada con los avances de la agricultura sobre usos forestales, que, dadas las condiciones particulares de ese espacio, convivieron con los aprovechamientos agrarios durante un tiempo ${ }^{8}$. El acondicionamiento de los canchales estaría relacionado con los intentos de fijación de un substrato eminentemente móvil y, por tanto, perjudicial para los sembrados y también para las terrazas inferiores, sobre las que potencialmente se podrían depositar lóbulos de derrubios; dinamismo que se muestra como una de las características intrínsecas de un medio eminentemente móvil ${ }^{9}$.

8. Esta cuestión se ha tratado con mayor profundidad en un artículo en proceso de evaluación de Giménez y Marco (inédito)

9. Marco (1988) 


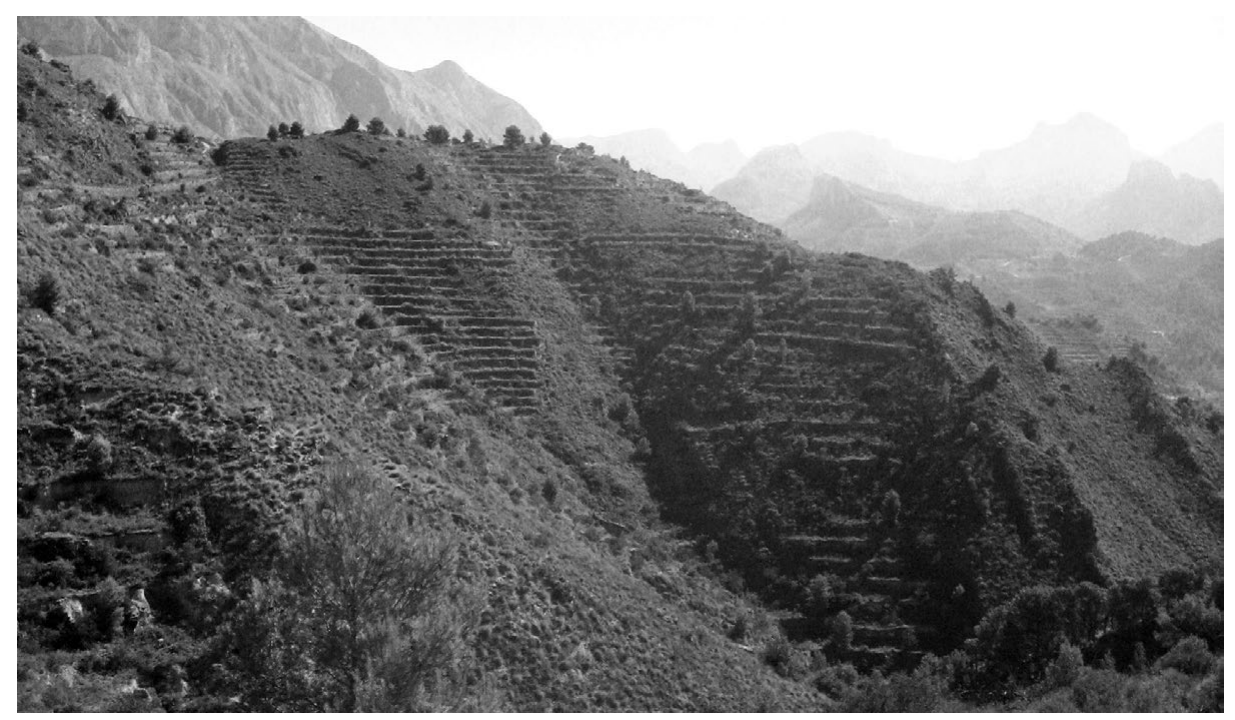

Figura 11. El Racó Ample (Relleu), representa un magnífico ejemplo de vertiente construida. Desde su base, las terrazas se levantaron en distintas fases y el origen es, de momento, desconocido. Sin embargo sabemos en la primera década del siglo xx se culminó el cerro con la construcción de un costoso bancal que obligó al despedregue de toneladas de piedra. La ingente tarea fue realizada por parte de Francisco García y sus seis hijos varones. Poco después de su finalización, todos ellos emigrarían a Francia y a Estados Unidos (fotografia del autor, 2011).

\section{REFLEXIÓN FINAL}

Desde la denominada arqueología del paisaje -en mi opinión, una disciplina heredera de la Geografía histórica- se han hecho avances significativos en algunas zonas de montaña mediterránea, con estudios ejemplares sobre la edad y evolución de terrazas a partir de diversos métodos; por otro lado la Geomorfología se ha encargado, especialmente a partir de los procesos de abandono, de valorar y evaluar aspectos morfológicos de la evolución de las vertientes aterrazadas, el control de la escorrentía o el incremento de tasas de erosión ${ }^{10}$.

Pero desde la óptica del presente planteamiento, el tratar de conocer el origen y los límites de la expansión de las terrazas tiene un sentido más transversal, con el fin de conocer las bases históricas del paisaje actual y su imbricación con las bases físicas que lo determinan. Con carácter retrospectivo, las terrazas y sus distintas fases de construcción ofrecen una información determinante para estimar el proceso de humanización de la montaña en su sentido más literal.

10. Sin ninguna intención de exhaustividad, se pretenden resaltar algunos artículos especialmente sugerentes, tanto en el plano de la datación (Harfouche, 2007; Grau y Pérez, 2008; Riera y Palet, 2008) como en el de la dinámica (Marco y Padilla, 1995; Lasanta et al. 2013). 
La masiva construcción de las vertientes y la expansión de la agricultura en detrimento de aprovechamientos forestales y ganaderos es un fenómeno relativamente reciente, lo que resulta una oportunidad para la investigación. La información -presente de forma más o menos directa en testimonios orales, documentos, morfologías constructivas, formaciones vegetales o sedimentospresenta la suficiente variedad y riqueza como para convertirse en un verdadero desafío científico.

Las presentes notas, fruto de observaciones de campo y fotointerpretación, no tienen otra finalidad que centrar una línea de investigación sobre la que, en mi opinión, todavía se ha escrito poco por parte de investigadores locales. Me gustaría atender así al reto que, desde hace años, me viene lanzando el profesor Alfredo Morales de forma insistente, preocupado ante el creciente descubrimiento de las terrazas de la montaña mediterránea por parte de autores anglosajones que, en muchas ocasiones, desconocen la trayectoria de estudios previos realizados por geógrafos, arqueólogos e historiadores de universidades españolas. Si bien los canales de difusión de la investigación española no han sido, muchas veces, los adecuados, tampoco lo son en ocasiones los canales de búsqueda bibliográfica a la hora de elaborar los state of the art. Con ello no se quiere minimizar ese déficit de atención que, llamativamente, han sufrido por nuestra parte estas estructuras agrarias tan habituales como sorprendentes. Ni tampoco se quisiera minusvalorar el papel del investigador local, un adjetivo tan maltratado como necesario para atender en su verdadera dimensión el origen y dinámica de uno de los paisajes culturales más destacables del mundo mediterráneo. Se trata, en suma, de poner en valor una de las lecciones transmitidas por el profesor Morales, defensor habitual de investigar sobre el paisaje vivido y sentido para alcanzar una comprensión cabal de la compleja realidad territorial que nos rodea.

\section{REFERENCIAS}

GimÉNEZ, P. y MARCO, J.A. (en proceso de evaluación): «La dinámica del paisaje en la Serra d'Aitana (Alacant, España): síntesis de transformaciones históricas en una montaña media mediterránea (1600-2010)»

GimÉNEZ, P. (2013): «La dinàmica del paisatge de terrasses de cultiu: algunes reflexions per al seu estudi a la Serra d'Aitana (País Valencià)», en Quaderns Agraris, n..$^{\circ} 34$, pp. $83-98$

HARFOUCHE, R. (2007): Histoire des paysages méditerranéens terrassés: aménagements et agriculture. Ed. Archaeopress, BAR International Series 1634. Oxford, pp. 265.

Hernández, M. y Morales, A. (2012): «Patrimonio agrario: paisaje y cultura en las riberas del Mediterráneo» en Los bienes culturales y su aportación al desarrollo 
sostenible. Servicio de Publicaciones de la Universidad de Alicante. Alicante, pp. 263-290.

Lasanta, T., Arnáez-Vadillo, J., Ruiz Flaño, P., y Lana-Renault, N. (2013): «Los bancales en las montañas españolas: un paisaje abandonado y un recurso potencial», en Boletín de la Asociación de Geógrafos Españoles, n. ${ }^{\circ}$ 63, pp. 301-322.

Marco, J. A. (1987). El Macizo del Maigmó: estudio de geografía física. Ed. Instituto de Estudios «Juan Gil Albert». Alicante, 171 pp.

Marco, J. A. y PAdilla, A. (1995): «Colonización vegetal en terrazas de cultivo abandonadas del sureste peninsular» en Cambios regionales a finales del siglo XX: XIV Congreso Nacional de Geografia: Comunicaciones. Ed. AGE-Universidad de Salamanca. Salamanca, pp. 38-42

Moll, M. y GimÉnez, P. (2014): «Propuesta metodológica para la restitución topográfica de espacios intensamente transformados» en Tecnologias de la Información Geográfica para nuevas formas de ver el Territorio. Universidad de Alicante-AGE. Alicante, pp. 438-447.

Morales Gil, A. (1992): «Orígenes de los regadíos españoles: estado actual de una vieja polèmica», en Gil Olcina, A. y Morales Gil, A. (coords.): Hitos históricos de los regadios españoles. Ed. Ministerio de Agricultura, Pesca y Alimentación. Madrid, pp. 15-48.

Morales Gil, A. y Marco, J. A. (1995): «Terrazas de cultivo abandonadas en el sureste peninsular: Aspectos evolutivos», en Investigaciones Geográficas, n. ${ }^{\circ} 13$, pp. 81-90.

Riera, S. y PaLeT, J. M. (2008): «Una aproximación multidisciplinar a la historia del paisaje mediterráneo: la evolución de los sistemas de terrazas con muros de piedra seca en la sierra de Marina (Badalona, Llano de Barcelona)», en Garrabou, R. y Naredo, J. M. (eds.): El paisaje en perspectiva histórica. Ed. Sociedad Española de Historia Agraria. Zaragoza, pp. 47-90

Sofia, G., Marinello, F., y Tarolli, P. (2014): «A new landscape metric for the identification of terraced sites: the Slope Local Length of Auto-Correlation (SLLAC)», en ISPRS Journal of Photogrammetry and Remote Sensing, n..$^{\circ}$ 96, pp. 123-133.

SOLER, E. (1994): El País Valenciano a fines del siglo XVIII: Carlos Beramendi y Freyre. Ed. Instituto de Estudios «Juan Gil Albert». Alicante, $222 \mathrm{pp}$.

ToRRó, J. (2005): «Terrasses irrigades a les muntanyes valencianes.: Les transformacions de la colonització cristiana», en Afers: fulls de recerca i pensament, $\mathrm{n}^{\circ}{ }^{\circ}$ 51, pp. 301-356

Torró, J. (2010): «Tierras ganadas. Aterrazamiento de pendientes y desecación de marjales en la colonización cristiana del territorio valenciano», en (Kirchner, E.) (ed.): Por una arqueología agraria. Perspectivas de investigación sobre espacios de cultivo en las sociedades medievales hispánicas. Ed. Archaeopress BAR International Series 2062. Oxford, pp. 157-172. 